\title{
Healing of Large Periapical with Tricalcium Silicate-based Root End Filling Material
}

\author{
${ }^{1}$ Snehal S Sonarkar, ${ }^{2}$ Rucheet Purba, ${ }^{3}$ Shishir Singh, ${ }^{4}$ Rajesh Podar
}

\begin{abstract}
Periradicular disease is mainly caused by varied microflora present in the root canal system. These microorganisms are removed to some extent with the help of various steps in root canal treatment. The infected teeth are treated nonsurgically rather than treating directly by surgical root canal treatment. For the successful surgical treatment, root end filling material is placed at the root end. This case report describes a case which is prior to nonsurgical method; however, because of complications these teeth are treated surgically. Biodentine being a biocompatible material can be used as a root end filling material, according to the manufacturer's instructions. The patient was recalled at a regular interval and it was found that periradicular tissue responded well to the restorative material. However, the long-term success rate for this material is yet to be evaluated, so for evaluation this case is followed up.
\end{abstract}

Keywords: Apicoectomy, Biodentine ${ }^{\mathrm{TM}}$, Endodontic microsurgery, Periradicular pathology, Periradicular surgery.

How to cite this article: Sonarkar SS, Purba R, Singh S, Podar R. Healing of Large Periapical with Tricalcium Silicate-based Root End Filling Material. Cons Dent Endod J 2016;1(2):41-45.

\section{Source of support: Nil}

Conflict of interest: None

\section{INTRODUCTION}

Nonsurgical root canal treatment (NSRCT) is often opted over surgical root canal treatment (SRCT). However, SRCT is indicated when there is persistent periradicular disease and when nonsurgical retreatment is impractical or unlikely to improve the previous results. ${ }^{1}$ This persistent root canal infection is because of varied microflora present within the root canal system. For

\footnotetext{
1,2 Senior Lecturer, ${ }^{3,4}$ Professor

${ }^{1}$ Department of Conservative Dentistry and Endodontics, VSPM's Dental College and Research Center, Nagpur, Maharashtra, India

${ }^{2}$ Department of Conservative Dentistry and Endodontics, Sri Venkateshwara Dental College, Bengaluru, Karnataka, India

${ }^{3,4}$ Department of Conservative Dentistry and Endodontics, Terna Dental College, Mumbai, Maharashtra, India

Corresponding Author: Snehal S Sonarkar, Senior Lecturer Department of Conservative Dentistry and Endodontics, VSPM's Dental College and Research Center, Nagpur, Maharashtra India, Phone: +919967111642, e-mail: snehalsonarkar@ gmail.com
}

healing of any periradicular disease bioactive repair materials have been used as a root end filling material. The various bioactive materials are calcium hydroxide introduced by Hermann in $1952,{ }^{2}$ mineral trioxide aggregate (MTA) introduced by Torabinejad et al, ${ }^{3,4}$ Biodentine $^{\mathrm{TM}}$ introduced by Septodont (Septodont, St. Maurdes Fossés, France) ${ }^{5}$ bioactive glass developed by Larry Hench, ${ }^{6}$ Diadent BioAggregate introduced by Diadent (DiaRoot, Diadent, Burnaby, Canada). ${ }^{7,8}$ These bioactive materials are used as a root end filling materials after root end cavity preparation and are considered as root end repair material against persistent periapical diseases. The other materials that have been used over ages are silver amalgam, intermediate restorative material (IRM), glass ionomer, etc.

Biodentine ${ }^{\mathrm{TM}}$ was launched in the year 2009 and has some similar properties to that of MTA. It is a tricalcium silicate-based material and has been used in restorative dentistry (pulp capping and dentin substitute) as well as in endodontics (root perforation, apexification, resorptions, and root end filling material). It has been proven as a biocompatible material according to various researchers. ${ }^{5,9-14}$

It has been proved that Biodentine ${ }^{\mathrm{TM}}$ has good healing capacity. It acts by proliferation, migration, and adhesion of human dental pulp stem cells, which in turn are activated by growth factors. ${ }^{10}$ It was also found that Biodentine $^{\mathrm{TM}}$ showed good marginal integrity and has ability to form hydroxyapatite crystals at the surface, thus increases the sealing ability. ${ }^{11,15,16}$ Biodentine ${ }^{\mathrm{TM}}$ enhances vascular endothelial growth factor (VEGF) and fibroblast growth factor (FGF-2), thus stimulating angiogenesis for healing pulpal fibroblasts. ${ }^{17}$

Thus considering the bioactivity, biocompatibility, and angiogenic properties of Biodentine ${ }^{\mathrm{TM}}$ it has been successfully used in the following case report.

\section{CASE REPORT}

A 25-year-old male patient reported to the Department of Conservative Dentistry and Endodontics with the chief complaint of discolored anterior tooth and palatal swelling. The patient gave a history of intermittent swelling in the palatal region, which lasted for about 4 to 6 days, with no history of pain during the duration 
of swelling or prior to swelling. A detailed medical and dental history was taken. The patient told the history of trauma since 10 years and the discoloration since 3 years.

On clinical examination discoloration was seen with right maxillary central incisor with no history of tooth fracture. Intraoral palatal swelling was seen with overall dimension of about $2 \times 2.5 \mathrm{~cm}$. It was soft, fluctuant, and distended. Anteroposteriorly, the swelling was situated between the line passing through distal margins of right and left maxillary canine (anteriorly) and the line from distal margin of maxillary right second premolar to distal margin of maxillary left first premolar (posteriorly). Mesiodistally, the swelling was situated from the midpalatine fissure centrally and laterally by line passing through the distal margin of maxillary right lateral incisor (Fig. 1A). There was no mobility present with the affected tooth with sound periodontium. Vitality test gave nonvital results with 11 to 13 when compared to other teeth. Intraoral periapical radiograph showed large periapical radiolucency with 11, 12 extending lateral to 13 , and then occlusal radiograph was taken so as to evaluate the extent of radiolucency (Figs 1B and C). The provisional diagnosis of palatal abscess was given. The treatment plan was root canal treatment with 11 to 13.
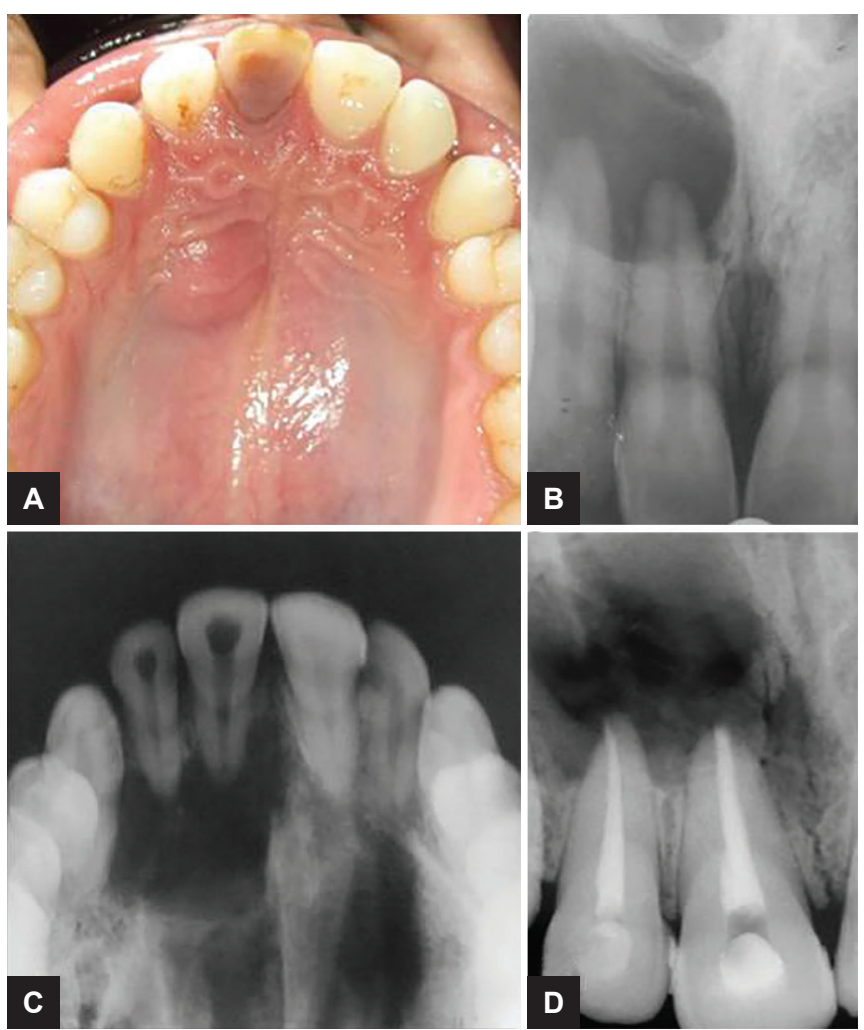

Figs 1A to D: Preoperative analysis: (A) Maxillary intraoral photograph showing palatal swelling; (B) intraoral periapical radiograph showing periradicular radiolucency with 11,12 ; (C) maxillary occlusal radiograph showing periradicular radiolucency with 11, 12; and (D) Post Obturation radiograph with 11, 12
The treatment plan was explained to patient, and patient's consent was taken. The patient was also explained about the surgical part.

Local anesthesia (lignocaine hydrochloride with adrenaline) was given and isolation was done with rubber dam (Hygienic Rubber Dam Kit, Coltene Whaledent, USA). Access opening was done with the help of large round bur and nonend cutting bur EX 24 (MANI, Inc., Dental products, Japan) and just after opening purulent drainage was seen through the canal. This purulent discharge was collected with the help of a sterile syringe ( $2 \mathrm{~mL}$ ) and sent for histopathological investigation.

The swelling was compressed and complete drainage was done. After complete evacuation canal was irrigated with $10 \mathrm{~mL}$ of normal saline (Baxter, Baxter India Pvt. Ltd., Aurangabad, India) till there was no discharge from the canal. The canal was dried with the help of paper points (Pearl Endopia, India) and was left opened for 6 hours. The patient was recalled and intracanal medicament (calcium hydroxide powder mixed with normal saline) was given. However, it was seen that after 30 minutes the swelling reappeared, so intracanal dressing was removed and open dressing was given. The swelling did not resolve, even after repeated open dressing and intracanal medicament. So as to overcome the problem, surgical treatment was planned. After complete cleaning and shaping, obturation was done just prior to surgery (Fig. 1D).

\section{Histopathological Report}

A smear layer for the purulent discharge was prepared on the slide and was stained with hematoxylin and eosin stain. In $100 \times$ magnification, chains in cocci were seen. Histopathologically, it was stated that the present organisms were Streptococci (Fig. 2). Hence, the final diagnosis of chronic alveolar abscess was given.

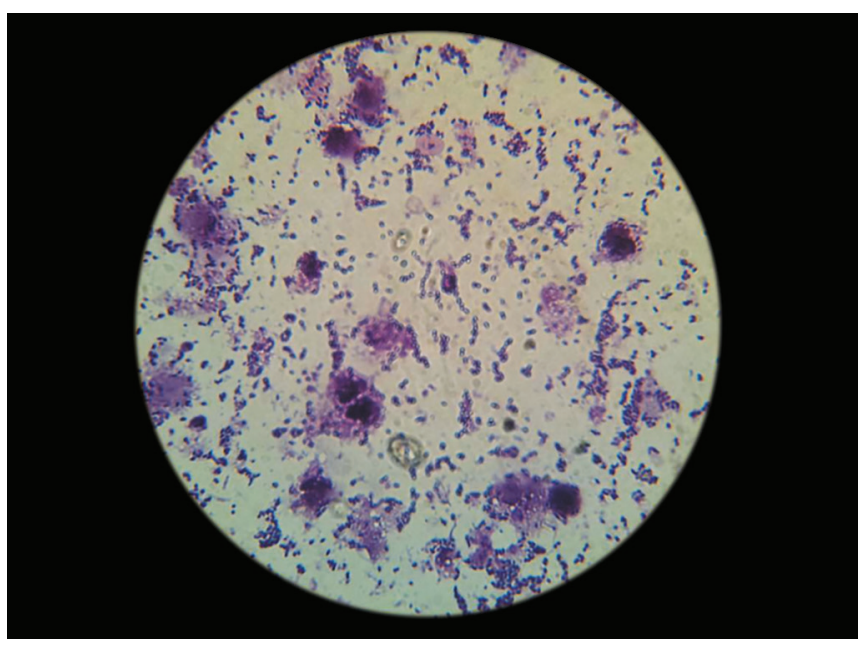

Fig. 2: Histopathological report showing cocci in chains 


\section{Surgical}

Surgical part was done under dental operating microscope (Seiler iQ 100-180, Seiler Precision Microscopes, St. Louis, USA) at 10× magnification. Local anesthesia (lignocaine hydrochloride and adrenaline in the ratio 1:50000) was given to maximize postoperative analgesia and minimize intraoperative bleeding. The patient was asked for signs and symptoms of anesthesia after 10 to 15 minutes.

An incision was given perpendicular to gingival margin with the help of microsurgical blade. The extent of incision was from distal of left central incisor and mesial of right first premolar (Fig. 3A). Then with the help of blunt instrument, a mucoperiosteal flap was raised. The defect was located and granulation tissue was completely excavated with the help of different types of excavators (CK Dental Specialties, Microsurgical Instruments, USA). The defect was excavated carefully as there might be chance of palatal perforation. To prevent this during curettage, the palate was supported by index

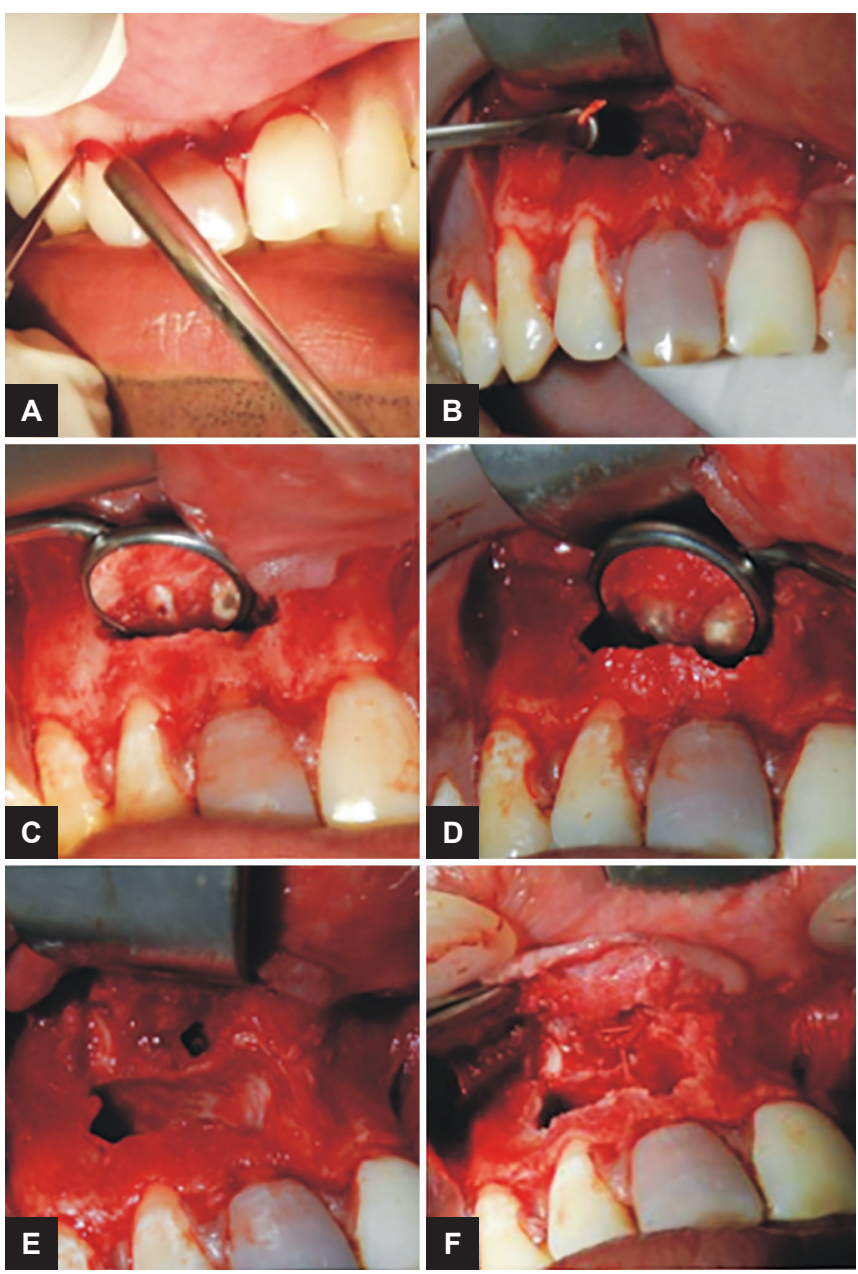

Figs 3A to F: Surgical procedure (Apicoectomy) with 11 and 12: (A) Incision given with the microsurgical blades, (B) reflection of flap, curettage, and supporting palate with the help of index finger, $(C)$ preparation of root end cavity with the help of ultra, (D) retrograde restoration with tricalcium Silicate based (Biodentine ${ }^{\mathrm{TM}}$ ) material, $(E)$ nasal perforation seen above the defect, and $(F)$ nasal perforation sutured with absorbable sutures finger (Fig. 3B). After complete excavation of granulation tissue, the defect was seen from mesial of canine laterally to mesial of left central incisor and was rinsed with the help of normal saline.

Then with the help of high-speed contra-angled handpiece apical $3 \mathrm{~mm}$ of tooth structure was removed, such that the resected surface is at right angle to the long axis of tooth for 11 and $12 .{ }^{18}$ Then with the help of root end cavity preparation tips root end cavity preparation was done and gutta-percha was compacted so that there is no gutta-percha on the walls (Fig. 3C). The borders of the defect were sharp, so they were rounded off with the help of a slow-speed micromotor. The osseous defect was washed thoroughly with normal saline and was inspected for any debris. Then, Biodentine ${ }^{\mathrm{TM}}$ was mixed according to the manufacturer's instruction and was placed in the root end cavity (Fig. 3D).

A nasal perforation was seen above the defect, so it was closed with the help of absorbable suture [VICRYL

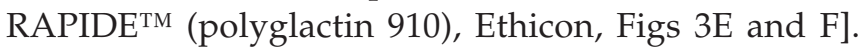
The defect was again analyzed, flap was approximated, and sutured with the help of vicryl suture. Postoperative instructions were given to the patient. Then the patient was recalled and sutures were removed. The tooth was discolored, so nonvital bleaching was performed with the help of sodium perborate and hydrogen peroxide. Then the patient was recalled bimonthly for evaluating the healing of defect. The periradicular healing for the case was shown in Figures $4 \mathrm{~A}$ to $\mathrm{C}$.

\section{DISCUSSION}

Nonsurgical root canal treatment is usually opted; however, in some cases SRCT is done, and is a challenge to endodontist. Surgical root canal treatment is a treatment option when the teeth are affected by biofilms known as extraradicular microbial biofilms. ${ }^{19}$ Nevertheless, for successful SRCT each and every step must be done carefully, thoroughly, and uneventfully. The teeth 11 to 13 were nonvital and patient did not experience any pain; however, palatal swelling reappeared, was distended when closed dressing was given and after placing intracanal medicament. The conservative treatment option would have been drainage by using drain tube or needle tip used in impression material. ${ }^{20}$ However, the patient insisted for immediate treatment as he experienced discomfort because of swelling.

A Cochrane Collaboration Review stated that the healing rate could be higher when the cases are treated surgically than cases treated nonsurgically. ${ }^{21}$ Elemam and Pretty ${ }^{22}$ found that the success rate of SRCT was 27.84 to $80 \%$. In SRCT, root end cavity preparation is done and restored with root end filling material. These root end filling materials are usually bioactive and are 


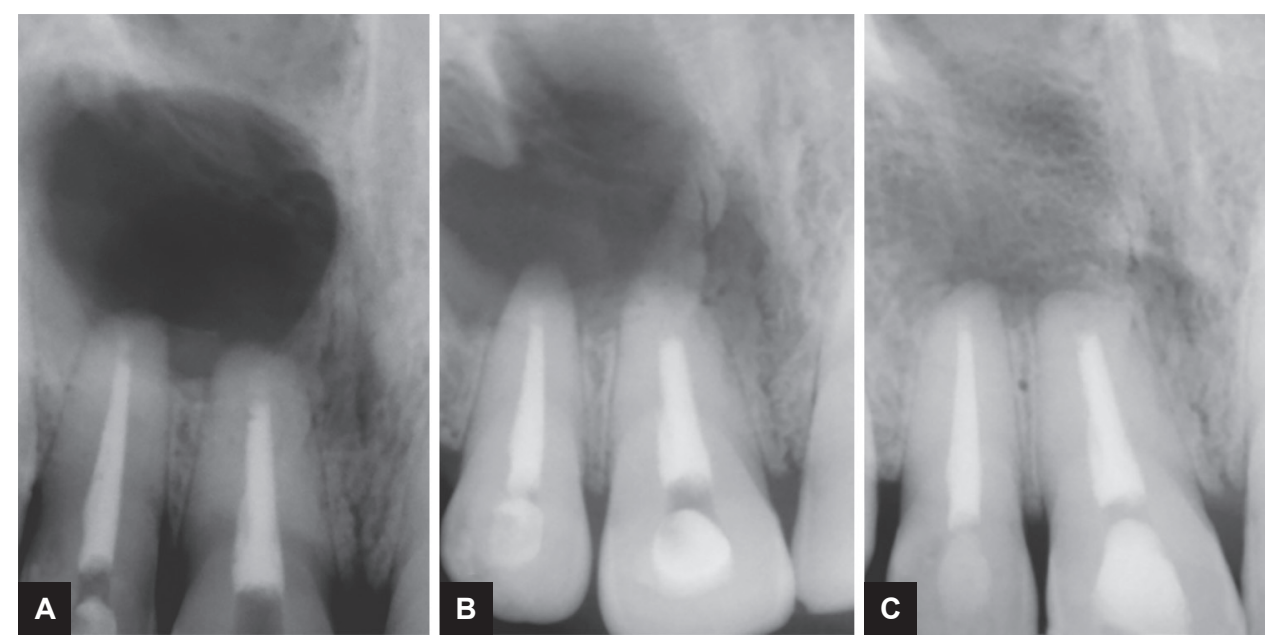

Figs 4A to C: Radiographs at different interval: (A) Immediate radiograph after surgery;

(B) recall after 6 months; and $(C)$ recall after 24 months

biocompatible, angiogenic, thus helps in uneventful healing of periradicular region.

The most commonly used material for restoring root end cavity is MTA. Biodentine ${ }^{\mathrm{TM}}$, being a bioactive material, has been used in the present case. It is dentin replacement material according to the manufacturer's instruction and can be used as root end filling material. Mineral trioxide aggregate has been used since decades as a root end filling material but the setting time of MTA is about $165 \pm 5$ minutes. ${ }^{23}$ However, Biodentine ${ }^{\mathrm{TM}}$ has very less setting time of about 8 to 10 minutes. The main drawbacks of MTA are its difficulty in handling, discoloration potential, toxic components in the material, high material cost, an absence of a known solvent for this material, and the difficulty of its removal after curing. ${ }^{24}$ It was also found that, if MTA is brought into contact with acidic primer or with excessive blood, it adversely affects the hydration reaction of MTA. ${ }^{25}$ However, Biodentine ${ }^{\mathrm{TM}}$ has all this advantages. It was also studied that microleakage of Biodentine ${ }^{\mathrm{TM}}$ is less than glass ionomer and MTA when used as a root end filling material. Thus, because of all these advantages, Biodentine ${ }^{\mathrm{TM}}$ was used in the present case.

It was found that there is reduction in size of the periradicular lesion (Fig. 4). This can be attributed to cytotoxic and angiogenic property of this root end filling material. The findings of this case report were in accordance with Pawar et $\mathrm{al}^{26}$ where they found reduction in size of periradicular pathology.

In the present case it was found that there was resolution of radiolucency in the periapical region when the patient was recalled after 24 months. These findings can be related to an in vitro study in which they found that Biodentine $^{\mathrm{TM}}$ showed better marginal adaptation than other materials. ${ }^{27}$ However, this result was in contrast to other study, which stated that the marginal adaptation of Biodentine $^{\mathrm{TM}}$ is less when compared to MTA and IRM. ${ }^{28}$

\section{CONCLUSION}

This case report has shown that the routine endodontic therapy followed by surgical intervention with a placement of biocompatible retrograde filling like Biodentine ${ }^{\mathrm{TM}}$ showed resolution of periapical radiolucency, and a good clinical result; therefore considered as a positive treatment outcome.

\section{REFERENCES}

1. Johnson BR, Fayad MI, Witherspoon DE. Chapter 11. Periradicular surgery. In: Hargreaves KM, Cohen S, editors. Cohen's pathways of the pulp. 10th ed. St. Louis (MO): Mosby; 2011; p. 721-722.

2. Hermann BW. On the reaction of the dental pulp to vital amputation and calxyl capping. Dtsch Zahnarztl Z 1952 Dec;7(24):1446-1447.

3. Torabinejad M, Hong CU, McDonald F, Pitt Ford TR. Physical and chemical properties of a new root-end filling material. J Endod 1995 Jul;21(7):349-353.

4. Torabinejad M, Chivian N. Clinical applications of mineral trioxide aggregate. J Endod 1999 Mar;25(3):197-205.

5. Biodentine ${ }^{\mathrm{TM}}$ - Publications and Communications 2005-2010. Research \& Development Septodont, Paris; 2010 [accessed 2014 Nov 26].

6. Valimaki VV, Aro HT. Molecular basis for action of bioactive glasses as bone graft substitute. Scand J Surg 2006;95(2): 95-102.

7. Yuan Z, Peng B, Jiang H, Bian Z, Yan P. Effect of bioaggregate on mineral-associated gene expression in osteoblast cells. J Endod 2010 Jul;36(7):1145-1148.

8. Park JW, Hong SH, Kim JH, Lee SJ, Shin SJ. X-Ray diffraction analysis of white ProRoot MTA and Diadent BioAggregate. Oral Surg Oral Med Oral Pathol Oral Radiol Endod 2010 Jan;109(1):155-158.

9. Han L, Okiji T. Uptake of calcium and silicon released from calcium silicate-based endodontic materials into root canal dentin. Int Endod J 2011 Dec;44(12):1081-1087.

10. Laurent P, Camps J, About I. Biodentine ${ }^{\mathrm{TM}}$ induces TGF$\beta 1$ release from human pulp cells and early dental pulp mineralization. Int Endod J 2012 May;45(5):439-448. 
11. Koubi S, Elmerini H, Koubi G, Tassery H, Camps J. Quantitative evaluation by glucose diffusion of microleakage in aged calcium silicate-based open-sandwich restorations. Int J Dent 2012;2012:105863.

12. Zhou HM, Shen Y, Wang ZJ, Li L, Zheng YF, Hakkinen L, Haapasalo M. In vitro cytotoxicity evaluation of a novel root repair material. J Endod 2013 Apr;39(4):478-483.

13. Perard M, LeClerc J, Watrin T, Meary F, Perez F, Tricot-Doleux S, Pellen-Mussi P. Spheroid model study comparing the biocompatibility of Biodentine and MTA. J Mater Sci Mater Med 2013 Jun;24(6):1527-1534.

14. Luo Z, Li D, Kohli MR, Yu Q, Kim S, He WX. Effect of Biodentine on the proliferation, migration and adhesion of human dental pulp stem cells. J Dent 2014 Apr 17;42(4):490-497.

15. Raju VG, Venumbaka NR, Mungara J, Vijayakumar $P$, Rajendran S, Elangovan A. Comparative evaluation of shear bond strength and microleakage of tricalcium silicate-based restorative material and radioopaque posterior glass ionomer restorative cement in primary and permanent teeth: an in vitro study. J Indian Soc Pedod Prev Dent 2014 Oct-Nov;32(4):304-310.

16. Malkondu Ö, Karapinar Kazandağ M, Kazazoğlu E. A review on biodentine, a contemporary dentin replacement and repair material. Biomed Res Int 2014;2014:160951.

17. About I 2009 Effects des matériaux bioactifs Biodentine ${ }^{\mathrm{TM}}$ et Calcipulpe ${ }^{\circledR}$ sur les étapes précoces de la régénération dentinaire. Report RD RA DEV 94-013. From Biodentine ${ }^{\mathrm{TM}}$ Publications and Communications 2005-2010. Research \& Development Septodont, Paris; 2010.

18. Kim S, Kratchman S. Modern endodontic surgery concepts and practice: a review. J Endod 2006 Jul;32(7):601-623.

19. Baumgartner JC, Siqueira JF Jr, Sedgley KM, Kishen A. Microbiology of endodontic disease. In. Ingle JI, Bakland LK, Baumgartner JC, editors. Ingles endodontics. 6th ed. Hamilton (ON): BC Decker Inc; 2008. p. 283.
20. Chandra BS, Krishna VG. Endodontic surgery. In: Chandra BS, Krishna VG. Grossmans endodontic practice. 12th ed. Wolters Kluwer Health (India); 2010. p. 419.

21. Del Fabbro M, Taschieri S, Testori T, Francetti L, Weinstein RL. Surgical versus non-surgical endodontic retreatment for periradicular lesions. Cochrane Database Syst Rev 2007 Jul;18(3):CD005511.

22. Elemam FR, Pretty I. Comparison of the success rate of endodontic treatment and implant treatment. ISRN Dent 2011;2011:640509.

23. Parirokh M, Torabinejad M. Mineral trioxide aggregate: a comprehensive literature review - Part I: Chemical, physical and antibacterial properties. J Endod 2010 Jan;36(1):16-27.

24. Parirokh $\mathrm{M}$, Torabinejad M. Mineral trioxide aggregate: a comprehensive literature review - Part III: clinical applications, drawbacks, and mechanism of action. J Endod 2010 Mar;36(3):400-413.

25. Seok-Woo Chang. Chemical characteristics of mineral trioxide aggregate and its hydration reaction. Restor Dent Endod 2012 Nov;37(4):188-193.

26. Pawar AM, Kokate SR, Shah RA. Management of a large periapical lesion using Biodentine $\mathrm{T}^{\mathrm{TM}}$ as retrograde restoration with eighteen months evident follow up. J Conserv Dent 2013 Nov-Dec;16(6):573-575.

27. RavichandraPV,Vemisetty H, DeepthiK, Reddy SJ, RamkiranD, Krishna MJN, Malathi G. Comparative evaluation of marginal adaptation of Biodentine ${ }^{\mathrm{TM}}$ and other commonly used root end filling materials - an in vitro study. J Clin Diagn Res 2014 Mar;8(3):243-245.

28. SoudappanS, Sundaramurthy JL, RaghuS, Natanasabapathy V. Biodentine versus mineral trioxide aggregate versus intermediate restorative material for retrograde root end filling: an in vitro study. J Dent (Tehran) 2014 Mar;11(2): 143-149. 